\title{
The Methods of enhancing the production on the wells completed by limited entry fracturing (LEF)
}

\author{
Xibo Chen ${ }^{1, \text { a }}$ \\ ${ }^{1}$ No.3 Oil Production Plant of Daqing Oilfield Company Ltd., Daqing, China \\ a42546826@qq.com
}

Keywords: Well completed by limited entry fracturing; Remain oil; liquid production per unit thickness; methods to enhence.

\begin{abstract}
In this paper we bring forward various kinds of methods to enhance the production of remain oil on the wells completed by limited entry fracturing through the analysis of the number of layers to be employed, remain oil distribution and the capacity of production of the wells. These methods are fracturing the non-limited entry layer, reperforating the limited entry layer, refracturing after the well perforated, plugging up water to the oil-layer that non-limited layer and high hydrous layer.
\end{abstract}

\section{Foreword}

A oil field is located in the south China and it has been explored about thirty years. The migration of oil and gas is mainly controlled by the South faults, lithologic pool with the fault block structure. Multilayer and each layer is not thick. Every well has an average of 21 layers, the average single layer thickness is only $0.7 \mathrm{~m}$. Complex lithology and poor mineral separation which mainly consists of grey mudstone and thin calcareous, and argillaceous dolomite siltstone[1]. Since 1999 more than 906 oil wells were drilled as the infilling adjustment wells in the region of A oil field. The refined geologic anatomy result show that the remain adjustable sandstone thickness is about $12.16 \mathrm{~m}$ and the effective thickness is $1.96 \mathrm{~m}$. The infilling ajustment has certain material base, but the remain oil planar distribution unbalance and vertical high dispersivity have determined the hardness of production potential development. Therefore, the approach should be started from technical and economical indexes to optimize well spacing with a possible better adjustment effect.

Among them there are 243 oil wells were completed by limited entry fracturing (LEF)and almost $26.8 \%$ of total, there are $61.9 \%$ thickness of sand layers were fractured by LEF after their perforation.

But now the water cut of the wells goes into higher hydrous level period. Effect of well fracturing is going down and down. In stead of that more than $26.8 \%$ of oil wells that completed by limited entry fracturing were not treated by anaphase stimulations yet and have great potential ability of production.

\section{Analysis of the number of layers to be employed and distribution of remain oil and the capacity of production of the wells.}

Goal layers of limited entry fracturing is mainly thin and poor and out-surface[2], after they were fractured the permeability get improved and get well used.

The percent to be employed is higher at the infancy of the well putting into production whether it is in or out-surface layer. That means the interformational contradiction is low and the employment of the poor layers get advanced. But the employment of limited entry fracturing layers is much higher than that of non-limited entry fracturing layers.

These variance of employment between non- limited and limited entry fracturing layers will be the principle object of enhance(table 1). 
Table 1 The number of layers to be employed of limited entry fractured (LEF) wells

\begin{tabular}{|c|c|c|c|c|c|c|c|}
\hline \multicolumn{2}{|c|}{ classify } & \multicolumn{2}{|c|}{ initial stage of production } & \multicolumn{3}{c|}{ at present } \\
\cline { 2 - 8 } \multicolumn{2}{|c|}{$\begin{array}{c}\text { number of } \\
\text { layers } \\
(\%)\end{array}$} & $\begin{array}{c}\text { thickness } \\
\text { of sand } \\
(\%)\end{array}$ & $\begin{array}{c}\text { effective } \\
\text { thickness } \\
(\%)\end{array}$ & $\begin{array}{c}\text { number of } \\
\text { layers } \\
(\%)\end{array}$ & $\begin{array}{c}\text { thickness } \\
\text { of sand } \\
(\%)\end{array}$ & $\begin{array}{c}\text { effective } \\
\text { thickness } \\
(\%)\end{array}$ \\
\hline \multirow{2}{*}{ Table-in } & no LEF & 45.3 & 49.0 & 45.3 & 60.5 & 66.9 & 75.8 \\
\cline { 2 - 9 } & LEF & 62.3 & 63.4 & 60.2 & 70.7 & 71.2 & 74.6 \\
\hline \multirow{2}{*}{ Table-out } & no LEF & 31.5 & 31.8 & & 37.2 & 37.8 & \\
\cline { 2 - 9 } & LEF & 45.4 & 43.1 & & 51.5 & 52.4 & \\
\hline
\end{tabular}

According to the information of the boracium-neutron well logging in the LEF wells, we know that the rate of no LEF layers employment is $12.3 \%$ higher than that of LEF layers, further, the number of water zones in non- LNF layers are larger and the number of oil-water zones in LEF layers are larger. This indicated that remain oil in the employed thickness in LEF layers is relatively higher and just few remain oil is in the no LEF layers that became high water zones and interfered the productivity of other poor and thin oil zones.

Rely on analysis above the main problem about formation employment of LEF wells is the different between LEF formations and no LEF formations. The employment of out-surface layer of LEF wells is better than that of no LEF wells, meanwhile, water layers and high-water layers of no LEF wells can also effect the employment of other poor and thin layers. There are many other contradictions in the formation inner and a great different employment between in and out-surface layers. The capacity of formation production is improved after well completed by LEF.

The principle of multi-layers limited entry fracturing are as follow: First, the numbers of perforations and their diameters are selected strictly, and then full pumping liquid is used during the treatment. Some formations is fractured, and because of just a few perforations so that can limited the entrance of fracturing fluid into formations, much friction resistence is produced and the bottom hole pressure growth higher. Fracturing fluid has to flow into other formations that may have higher fracturing pressure to fracture other formations one by one.

In order to realize the limited entry fracturing one formation just be perforated by one hole that max diameter can reach $7.2 \mathrm{~mm}$. But along with the growth of hydrous and intensity of liquid production enlarged that one hole can not satisfy necessary of production.

If the production of a formation that just perforate one hole is larger than $2.7 \mathrm{t} / \mathrm{d}$, the amount of the hole will be not satisfy the need of liquid production. Non-radial flow will be appeared that restrict production ability of this formation.

From the relationship of hydrous and intensity of liquid production we can understand it better. From the initial stage to $65 \%$ hydrous the intensity of liquid production of LEF well is higher than that ordinary wells. But ordinary well can promote its production evidently by stimulations such as fracturing and so on.

\section{Examples}

Fracturing to non-LEF layers. According to the analysis of remain oil no LEF layers in the LEF wells have much thickness that are not put into use, so they have great potential production ability if they are fractured. For example, $\mathrm{C} 1$ is a LEF well. Perforated sand thickness is $23.2 \mathrm{~m}$, effective thickness $5.1 \mathrm{~m}$, index of formation is $0.159 \mu \mathrm{m}^{2}$, the no LEF formations are $50.4 \% 、 38.3 \%$ and $11.3 \%$ out of total. Now this well can produce liquid $21 \mathrm{t} / \mathrm{d}$, oil $7 \mathrm{t} / \mathrm{d}$, water cut $66.7 \%$ and liquid flow pressure is $1.49 \mathrm{MPa}$. There are 4 injection wells around it and its injection-recovery systems is perfect and have good conditions to increase its production by fracturing. Make a general fracturing to no LEF formations of this well on November in 1998. After fracturing the liquid increase 24t/d, oil production increase $11 \mathrm{t} / \mathrm{d}$ and hydrous decrease $5.0 \%$, flow pressure and level rising, skin factor changed from 5.796 to -3.913 . effictiveness of fracturing is evident. 
Re-fracturing the LEF formations. Re-perforate on the LEF intervals to increase the density of perforation

For a single formation sometimes we only perforate one hole within the LEF intervals. Along with the hydrous increased liquid production per unit thickness goes up and friction resistence of perforations increase also, so in some layers can occur no radial flow that restrict the production ability. At the same time, the LEF formations are much diversity. If these formations are re-perforated, their perforation density and the sweep-oil volume increased we should get better effectiveness of oil field development.

It was considered that there are many conflicts between and among the different formations within the LEF intervals, we decide to use normal perforation means to re-perforate the casing of the LEF layers. We chose 4 wells to re-perforate the LEF layers ( Table 2 ). After fracturing 7.6t/d of liquid and $3.8 \mathrm{t} / \mathrm{d}$ of oil is increased, otherwise water cut decreases $8.7 \%$.

Table 2 Production data of re-perforating LEF wells

\begin{tabular}{|c|c|c|c|c|c|c|c|c|}
\hline \multirow{2}{*}{$\begin{array}{c}\text { well } \\
\text { number }\end{array}$} & $\begin{array}{c}\text { liquid } \\
\text { production } \\
(\mathrm{t} / \mathrm{d})\end{array}$ & $\begin{array}{c}\text { oil production } \\
(\mathrm{t} / \mathrm{d})\end{array}$ & $\begin{array}{c}\text { water cut } \\
(\%)\end{array}$ & $\begin{array}{c}\text { bore hole } \\
\text { production } \\
\text { pressure } \\
(\mathrm{MPa})\end{array}$ & $\begin{array}{c}\text { liquid } \\
\text { production } \\
(\mathrm{t} / \mathrm{d})\end{array}$ & $\begin{array}{c}\text { oil production } \\
(\mathrm{t} / \mathrm{d})\end{array}$ & $\begin{array}{c}\text { water cut } \\
(\%)\end{array}$ & $\begin{array}{c}\text { bore hole } \\
\text { production } \\
\text { pressure } \\
(\mathrm{MPa})\end{array}$ \\
\hline $\mathrm{C} 1$ & 14.2 & 6.1 & 55.6 & 2.6 & 29.1 & 8.2 & 71.8 & 2.7 \\
\hline $\mathrm{C} 2$ & 18.3 & 5.2 & 69.7 & 3.0 & 28.9 & 7.1 & 75.4 & 3.4 \\
\hline $\mathrm{C} 3$ & 13.1 & 1.3 & 91.0 & 1.6 & 30.2 & 5.4 & 82.1 & 1.9 \\
\hline C4 & 16.3 & 2.7 & 83.5 & 2.2 & 31.6 & 6.7 & 78.8 & 2.6 \\
\hline Total & 61.9 & 15.3 & 73.3 & 2.2 & 119.8 & 27.4 & 77.1 & 2.7 \\
\hline
\end{tabular}

The LEF well can be fractured after its re-perforating. Re-perforating on the LEF intervals can improve bore hole completion degree and influent condition to some degree. If water inject is efficiency, we can choose a certain kind of fracturing and a good result will be obtained. For example, $\mathrm{C} 2$ well,after it re-perforating liquid production increases $9 \mathrm{t} / \mathrm{d}$,oil production increases $3 \mathrm{t} / \mathrm{d}$, formation pressure go up and flow pressure has no change. According to the analysis to the information of well logging, analysis of dynamic and static state we found that many influent conflicts among the formations so that we decide to re-fracturing the layers that were limited entry fracturing at the initial stage of well completed. After fracturing, the production of liquid increased $29 \mathrm{t} / \mathrm{d}$ and oil is increased $10 \mathrm{t} / \mathrm{d}$, otherwisehydrous decreased. It is a very successful example and we obtain a good result.

Depreciate conflicts among the formations by water plugging in the high water cut formations. Rely on the analysis above, it was considered that the main reason of arousing integrate water cut growth quickly is no LEF formation water cut goes up much higher. For example, C3 well can produce $51 \mathrm{t} / \mathrm{d}$ liquid and its water cut is $95.7 \%$. the data of Boron neutron well logging indicated that there is a high water cut layer in the no LEF intervals and its sand perforation thickness is $6.3 \mathrm{~m}$ and effectiveness $3.1 \mathrm{~m}$ that is $42.2 \%$ and $40.0 \%$ in total. According to the well production logging data we know that more than $51 \%$ of the total production was produced by this high water cut layer. After well water plugging, the well only produces liquid $11 \mathrm{t} / \mathrm{d}$, oil $4 \mathrm{t} / \mathrm{d}$ and water cut $63.6 \%$. Effect of the treatment is perfect.

\section{Brief summary}

In the early stage of LEF well the permeability of thin and poor formations has improved effectiveness that increase the layers to be employed and ability of production. These wells make a great of contributions on oil stabilizing and water control technology.

There are much different of layer employment and its degree of hydrous between LEF and no LEF the formations in LEF wells. That means there are great many conflicts among and in the different 
formations, these also exert in the inner of two sort of in and out surface layers so there is much remain oil can be turnout by taking some of means.

Anaphase Method of enhancing the production on the wells completed by limited entry fracturing is to be fractured the non-limited entry layer, reperforated the limited entry layer, refractured after the well perforated,

plugged up water to the oil-layer that no-limited layer and high hydrous layer.

\section{References}

[1].Fu Daoming,Wu Xiaodong,etal.Science Technology and Engineering,2010;10(1):213.

[2].Jin Yusun. Production Geologic Engineering [M] .Beijing: Petroleum Industry Press,1985. 